\title{
Waste minimisation: home digestion trials of biodegradable waste
}

\author{
M. L. Bench, R. Woodard, M. K. Harder, N. Stantzos, \\ Waste and Energy Research Group (WERG), Faculty of Science and Engineering, \\ University of Brighton, East Sussex, BN2 4GJ, UK \\ Tel: +44 (0) 1273642391 \\ Fax: +44 (0) 1273642285 \\ E-mail address: m.k.harder@bton.ac.uk
}




\begin{abstract}
Minimisation of municipal solid waste and diversion from landfill are necessary for the UK to manage waste sustainably and achieve legislative compliance. A survey of householder attitudes and experiences of a trial for minimising household food waste from waste collection in the county of West Sussex, UK is described. The minimisation method used the Green Cone food digester, designed for garden installation. A postal questionnaire was distributed to 1,000 householders who had bought a cone during the trial and a total of 433 responses were received. The main reason for people buying the Green Cone had been concerns about waste (88\%), with $78 \%$ and $67 \%$ of respondents respectively claiming to have participated in recycling and home composting in the last 30 days. The waste material most frequently put in the digester was cooked food (91\%), followed by fruit waste, vegetable matter and bones/ meat. Some respondents were using it for garden and animal waste from pets. Most users found the Green Cone performed satisfactorily. Approximately $60 \%$ of respondents had seen a reduction of $25-50 \%$ in the amount of waste they normally put out for collection, with analysis showing reported levels of reduction to be significant $(\mathrm{p}<0.05)$. Additional weight surveys by householders recorded an average of $2.7 \mathrm{~kg} / \mathrm{hh} / \mathrm{wk}$ diverted to the food digester.
\end{abstract}

Keywords: Waste minimisation; Household waste; Biodegradable; Kitchen waste; Attitudes; Performance; Composition

\title{
1. Introduction
}

Household waste minimisation is a crucial component of the UK waste strategy and sustainable waste management, where avoidance of waste altogether is a preferable option to re-use and recycling (DETR, 2000). In the context of household waste, minimisation is often used to imply diversion of waste to garden composters or food digesters. Waste minimisation is, however, difficult to implement and public programs can require 
considerable financial resources from local authorities. The outcomes from these programs can also be difficult to measure in terms of actual waste reduction and the returns are rarely cost effective (Tonglet et al., 2004). Moreover, while there has been a wealth of research into recycling behaviour, less attention has been given to municipal solid waste minimisation with few detailed published reports on the subject in the UK (Tonglet et al., 2004).

One of the major components of household waste is putrescible or biodegradable material such as kitchen waste, typically comprising 17 to $22 \%$ by weight of an average household's waste in the UK (Parfitt, 2002; Poll, 2002) and may include vegetable, fruit and cooked and processed foods. Such wastes are now subject to the EU Landfill Directive (99/31/EC) which came into effect in the UK on 16 July 2001 (DETR, 1999).

The Landfill Directive requires a reduction of biodegradable waste entering landfill to $75 \%$ of the 1995 levels by 2006, 50\% by 2009 and 35\% by 2016 (DETR, 1999). Failure to achieve these targets by the required date would ultimately result in penalties and sanctions for non-compliance from the European Court. It is therefore imperative that local authorities in the UK make significant progress on this issue.

One approach that can be adopted by local authorities is to minimise the kitchen waste components of household waste entering the collection stream, through the provision of subsidised waste digesters to residents. It was on this basis that West Sussex County Council (WSCC) in southern England conducted a trial of the Green Cone food and kitchen waste digester. 
The Green Cone (Fig. 1) is designed for garden installation to enable solar energy to enhance microbial activity and accelerate the decay of biodegradable household kitchen waste. The product is made from plastic and consists of three main components; the inner cone, outer cone and basket. The basket is buried in the soil and acts as the repository for the waste, while the cone is positioned above ground so as to absorb significant solar radiation and raise the temperature of the waste. Waste is deposited by the householder through the lid at the top (Green Cone, 2003).

\section{Method}

The main aim of this research was to examine householder attitudes to the use and performance of the digester and if it was effective at minimising household waste.

\section{INSERT FIGURE 1}

The research employed questionnaire surveys of residents and a sample group of 48 households to weigh the material being put in their digesters. The trial began with a sales promotion for the Green Cone at supermarkets throughout West Sussex, UK, with a total of 2,123 digester units sold and contact details of customers retained in a database.

\subsection{Postal questionnaire}


In the first stage of the research a questionnaire was posted to 1,000 households out of the 2,123 West Sussex residents who had bought the Green Cone. The survey was designed to test attitudes to the digester and its potential for waste minimisation. Information was sought on basic demographics, attitudes to recycling and composting and issues or problems experienced by householders using the Green Cone.

\subsection{Weight survey}

A total of 48 volunteer households were also recruited across West Sussex. The residents were provided with a spring balance and data recording sheet and asked to weigh their contents of the kitchen caddy before the contents were emptied into the Green Cone. Typically, the kitchen caddy, which is a small plastic container supplied with the Green Cone, is designed to hold $1-2 \mathrm{~kg}$ of waste.

\section{Results}

\subsection{Demographics}

A total of 433 completed questionnaires were returned representing a response rate of $43 \%$. A selection of the sample demographics is described in Tables 1 and 2 below. They include responses in relation to gender, age, household composition, dwelling type and garden size. Approximately $25 \%$ of the households were comprised of couples aged 55 and over, and

INSERT TABLE 1 AND 2 
$8 \%$ were between 35 and 54 years (Table 2). $28 \%$ of households were comprised of 2 parents with children and half of these (14\%) had both parents in the 35-44 age range while $4 \%$ had younger parents, aged between 25-34 years. Only 3\% of households had single parents with children and $7 \%$ of households had multiple adults with children. The majority of the single occupancy households (5\%) had residents of 55 and over.

Most respondents were female (269), and with 150 males and 14 who did not specify (Table 2). Further analysis showed that $43 \%$ of the females who answered the questionnaire were responsible for buying the Green Cone. Only $26 \%$ of males who answered the questionnaire were also the person who had bought the food waste digester.

The most frequently occurring type of housing was detached, followed by semi-detached (two houses sharing one wall) and bungalows (single storey houses). A very small number of respondents occupied flats (apartments). A comparison with the dwelling types known for the county overall is also provided (National Statistics, 2003), which shows a degree of overrepresentation in the sample of detached and semi-detached categories and underrepresentation of terraces and flats. Approximately $38 \%$ of respondents claimed mediumsized gardens but most people (43\%) reported large gardens.

\subsection{Attitudes to the Green Cone and recycling}

A high percentage of respondents, $88 \%$, stated that they had bought the Green Cone because they were concerned about the amount of rubbish they produced (Table 3). Many people were also curious about the concept, while others considered it would be a complement to an existing compost bin. 
The majority of respondents also claimed to have participated in some form of recycling within a 30-day period. $78 \%$ for kerbside box schemes and $83 \%$ for mini-recycling centre schemes (also called bring schemes) (Fig. 2). Furthermore, many stated they purchased products made from recycled material and currently used compost bins. Therefore, attitudes to recycling were generally positive.

\subsection{Locating the Green Cone}

Most respondents (69\%) did not experience any difficulty in finding a suitable location in their garden for the digester. However, comments were received from 119 people that did

\section{INSERT TABLE 3}

INSERT FIGURE 2

experience difficulties (Table 4), which included trying to locate the Green Cone in the sun (56\%), finding a discreet position (28\%), hard/clay soil (14\%) and lack of space (12\%).

\subsection{Problems experienced during use}

A total of 395 people out of the 433 surveyed experienced at least one problem while using the Green Cone. The most frequent experience was flies, which accounted for $69 \%$ out of the total problems reported (Fig. 3) followed by slow decay (53\%).

Odour from the digester was also a problem for some people. However, no one actually experienced all the potential problems listed in the questionnaire, although $20 \%$ of people indicated that the problems they had experienced had stopped them using the cone altogether 
(Table 5). In at least 9 cases, for flies and slow decay, the respondents said they would only be stopping temporarily to provide enough time for the problem to remedy itself. Therefore, a total of 72 people or $17 \%$ of the total 433 respondents were identified to have stopped using the Green Cone completely.

\section{INSERT TABLE 4}

INSERT FIGURE 3

\subsection{Digestive performance}

When asked to express how the Green Cone was performing as a waste digester $49 \%$ of people said it was performing well to very well and $29 \%$ of respondents were undecided. $19 \%$ thought it was performing poorly to very poorly, which provides a level of consistency with the $17 \%$ of respondents who stopped using their Green Cones for various reasons.

\subsection{Reduction in waste normally put out for collection}

Residents were asked to indicate how much they thought they had reduced the amount of rubbish they normally put out each week since installing the digester. Almost $60 \%$ indicated a reduction of $25-50 \%$. Fig. 4 shows the variation in the reduction reported with number of occupants in the house. A statistically significant correlation was found for ANOVA with pvalue $<0.05$. A similar correlation exists for the number of bags of waste set out before installation of the digester indicating a clear causal effect reported.

\section{INSERT TABLE 5}

INSERT FIGURE 4 


\subsection{Waste composition}

The composition of waste being placed in the Green Cone as recorded by the responding households is summarised in Fig. 5. The most frequently occurring wastes were cooked

\section{INSERT FIGURE 5}

\section{INSERT FIGURE 6}

foods, fruit and vegetable matter. Besides typical food wastes, garden and animal wastes were also present in the composition, albeit at a low frequency.

\subsection{Weight survey results}

The 48 volunteer households diverted a total of $782 \mathrm{~kg}$ to the Green Cones during the six week survey period. A mean waste arising of $16.3 \mathrm{~kg}$ per household was recorded or $2.7 \mathrm{~kg}$ per household per week. The waste per household was highly variable (standard deviation 10.1) (Fig. 6) with a similar recorded composition to that provided by the results from the questionnaire survey.

\section{Discussion}

The majority of the respondents were aged 35-54, female and claimed to be recyclers. Previous research suggests that these groups are most likely to recycle and therefore age and gender are significant predictors in recycling frequency (Lyas et al., 2002). Older residents and females are more likely to participate with women scoring higher on environmental responsibility scales than men (Ebreo et al., 1999). The results from this investigation 
provide evidence that these groups are also willing to participate in waste minimisation. Attitudes strongly influence waste reduction and are related to societal benefits such as helping the environment; self-efficacy, a belief that one can make a difference (Taylor and Todd, 1995).

Although many respondents experienced one or more problems during the use of the Green Cone, in only $17 \%$ of cases were these considered significant enough to stop them from using the digester altogether. Furthermore, in 9 cases where people had stopped, they were prepared to begin again once the problem had ceased. Locating and installing the Green Cone in the garden presented some difficulty for approximately $27 \%$ of users but these were mostly overcome. Both of these results may be influenced by the positive attitude the sample group had towards recycling and composting. However, from a limited sample size it is not possible to determine how such attitudes may be representative of the wider population and how this could ultimately limit a more widespread adoption of the Green Cone.

Dwelling type and garden size are also likely to be influential, and the degree of greater representation of the larger housing units of detached and semi-detached in the sample compared to West Sussex as a whole requires further investigation. However, the results for garden size indicate the Green Cone is more likely to be used in large- to medium- sized gardens although it is still suitable for small gardens.

In terms of the reported waste composition, the digester is receiving some materials that could not go in a traditional compost bin, such as cooked food waste. Moreover, the Green Cone is only receiving small amounts of garden waste. This demonstrates that the use of home compost units and Green Cone digesters in the same garden would be complementary. The presence in the cones of animal waste, paper and card also shows that the scope for 
diversion of materials from the household collection is not limited to food waste. Fundamentally, because the most frequently occurring wastes such as fruit, vegetable peelings and cooked foods form a large proportion of the composition by weight of a dustbin, their removal from the domestic collection would be expected to reduce collected weights. The potential levels of waste minimisation are supported by responses and weight surveys indicating there is a reduction in numbers of refuse sacks placed out for weekly household collection with recorded mean weekly reductions of $2.7 \mathrm{~kg}$ per household.

\section{Conclusions}

This paper reports on a survey of 433 current users of the Green Cone food waste digester. Although the majority of respondents experienced some form of problem in relation to using the food waste digester, in the majority of cases this did not lead to the householder ceasing to use it. Therefore, the results show that home biodegradable waste digestion has the potential to make a significant contribution to household waste minimisation and the diversion of biodegradable waste from landfill. Not only can this help with legislative compliance but it could also lead to collection and disposal cost reductions for local authorities. Further work should consider the extent to which the attitudes of householders to waste issues can influence the acceptability and adoption of food waste digestion over a wider area.

\section{Acknowledgements}


The authors would like to thank West Sussex County Council, Environmental and Economic Policy Service for their assistance with this research.

\section{References}

DETR., 1999. Limiting Landfill: a consultation paper on limiting landfill to meet the EC Landfill Directive's targets for the landfill of Biodegradable Municipal Waste. HMSO, London, UK.

DETR., 2000. Waste Strategy for England and Wales. HMSO, London, UK.

Ebreo, A., Hershey, J. and Vining, J., 1999. Reducing solid waste: linking recycling to environmentally responsible consumerism. Environ. Behav., 31(1):107

Green Cone., 2003. Available: http://www.greencone.com.

Lyas, J., Shaw, P. and Van-Vugt,. M., 2002. Survival bag behaviour in a London borough: householder behaviour, motivations and barriers. IWM Proceeding.

Office for National Statistics., 2003. Available:

http://www.statistics.gov.uk/census2001/default.asp.

Poll, J., 2002. Pilot study on municipal waste composition in Wales. AEA Technology, Harwell, UK. 
Parfitt J., 2002. Analysis of household waste composition and factors driving waste increases. WRAP, Banbury, UK.

Taylor S, Todd P. An integrated model of waste management behaviour: a test of household and composting intentions. Environ. Behav., 27 (5): 603-630.

Tonglet, M., Phillips, P. S. and Bates, M. P., 2004. Determining the drivers for householder pro-environmental behaviour: waste minimisation compared to recycling. Resour. Conserv. Recycl., 42: 27-48 

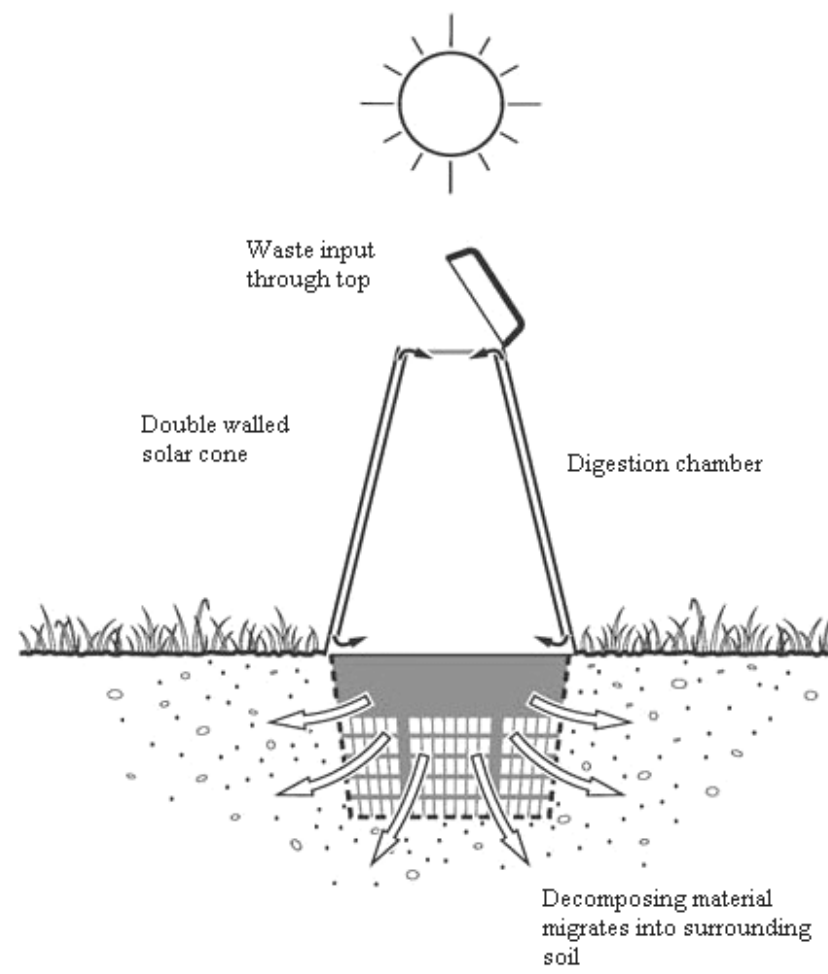

Fig. 1. Diagram of an installed Green Cone (Green Cone, 2003) 
Table 1. Summary of categories of households responding

\begin{tabular}{lccc}
\hline Household Category & $\begin{array}{c}\text { Age range of } \\
\text { resident adults }\end{array}$ & $\%$ & $\mathrm{~N}$ \\
\hline Single occupancy & $55+$ & 5 & 21 \\
Single occupancy & $35-54$ & 2 & 8 \\
Single occupancy & $<35$ & 1 & 3 \\
Couple & $55+$ & 25 & 109 \\
Couple & $35-54$ & 8 & 33 \\
Couple & $<35$ & 2 & 9 \\
Couple mixed aged & all & 4 & 17 \\
Parents with children & $45+$ & 4 & 16 \\
Parents with children & $35-44$ & 14 & 60 \\
Parents with children & $25-34$ & 4 & 18 \\
Parents-mixed age- with children & all & 6 & 27 \\
Single parents with children & $35-74$ & 3 & 12 \\
Multiple adults $(3+>18$ yrs) & all & 11 & 46 \\
Multiple adults $(3+>18$ yrs) plus children & all & 7 & 31 \\
No data & & 5 & 23 \\
\hline Total & & 100 & 433 \\
\hline
\end{tabular}


Table 2. Respondent gender, approximate garden size and dwelling type

\begin{tabular}{lccllllllc}
\hline Gender & $\mathrm{N}$ & $\%$ & Garden size & $\mathrm{N}$ & $\%$ & Dwelling type & $\mathrm{N}$ & $\%$ & $\%$ West Sussex \\
& & & & & & & & & \\
\hline Female & 269 & 62.1 & Large & 184 & 42.5 & Bungalow & 62 & 14.3 & - \\
Male & 150 & 34.6 & Medium & 164 & 37.9 & Terraced & 56 & 12.9 & 23 \\
Other & 1 & 0.2 & Small & 68 & 15.7 & Semi-detached & 125 & 28.9 & 27 \\
No answer & 13 & 3.0 & Other & 1 & 0.2 & Detached & 179 & 41.3 & 30 \\
& & & No answer & 16 & 3.7 & Flat & 5 & 1.2 & 20 \\
& & & & & & Other & 1 & 0.2 & - \\
& & & & & & No answer & 5 & 1.2 & - \\
\hline Total & 433 & 100 & Total & 433 & 100 & Total & 433 & 100 & 100 \\
\hline
\end{tabular}


Table 3. Reasons provided by respondents for buying the Green Cone

\begin{tabular}{lc}
\hline Reason & \% in agreement \\
\hline Liked design of product & 42 \\
As a complement to a composting bin & 53 \\
As a gift for someone & 3 \\
Curious about the concept & 68 \\
Concerned about the amount of rubbish & 88 \\
\hline
\end{tabular}




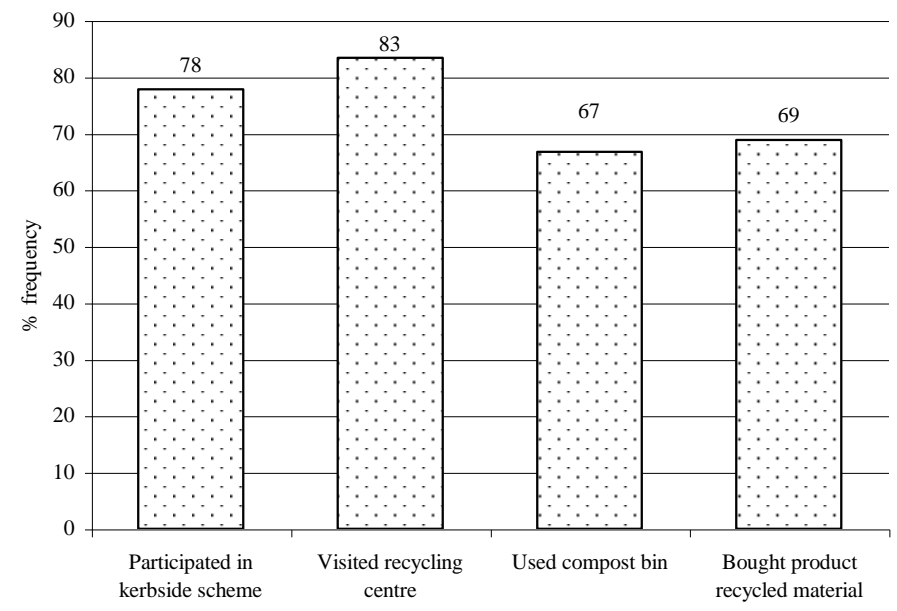

Fig. 2. Level of participation in other recycling related activities in the past 30 days 
Table 4. Comments from respondents that experienced difficulties with locating the digester.

\begin{tabular}{lc}
\hline Difficulty experienced & As a \% of respondents (119) \\
\hline Locating in sun & 56 \\
Inconspicuous/discreet position & 28 \\
Clay/hard soil & 14 \\
Space & 12 \\
Access & 8 \\
Digging in & 5 \\
High water table/flooding & 4 \\
Tree roots & 4 \\
Pipes & 2 \\
Other & 17 \\
\hline
\end{tabular}




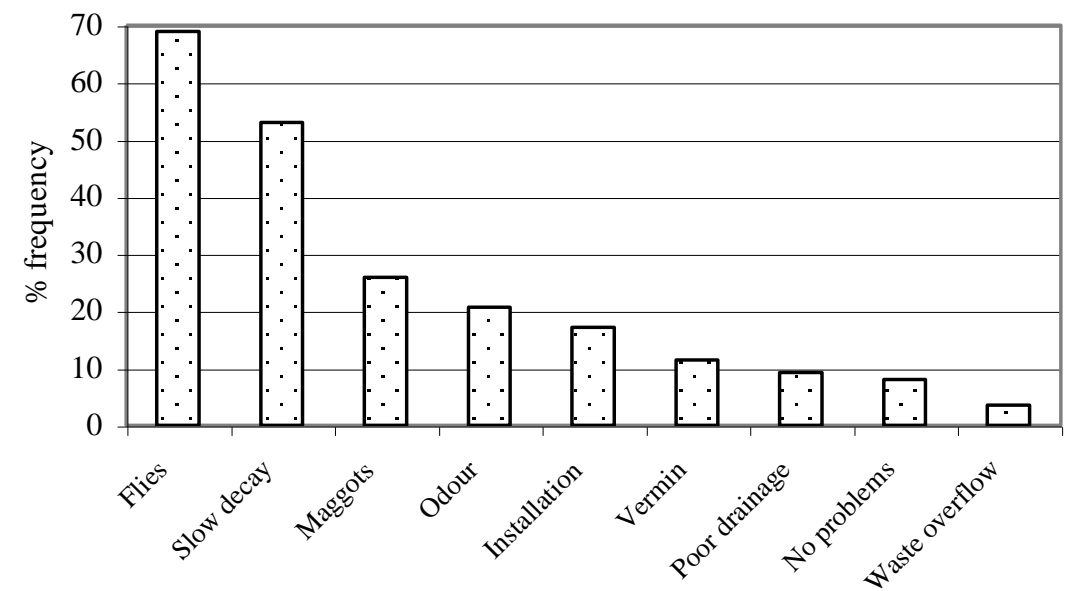

Fig. 3. Problems experienced by householders during use of the Green Cone 
Table 5. Reasons for stopping use of the Green Cone altogether/ temporarily

\begin{tabular}{lc}
\hline Reason & Number of comments \\
\hline Flies and maggots & 27 \\
Slow decay & 15 \\
Vermin & 14 \\
Odour & 10 \\
No reason given & 9 \\
Slow decay-only stopping temporarily & 6 \\
Flies- only stopping temporarily & 3 \\
\hline Total comments & 84 \\
\hline
\end{tabular}




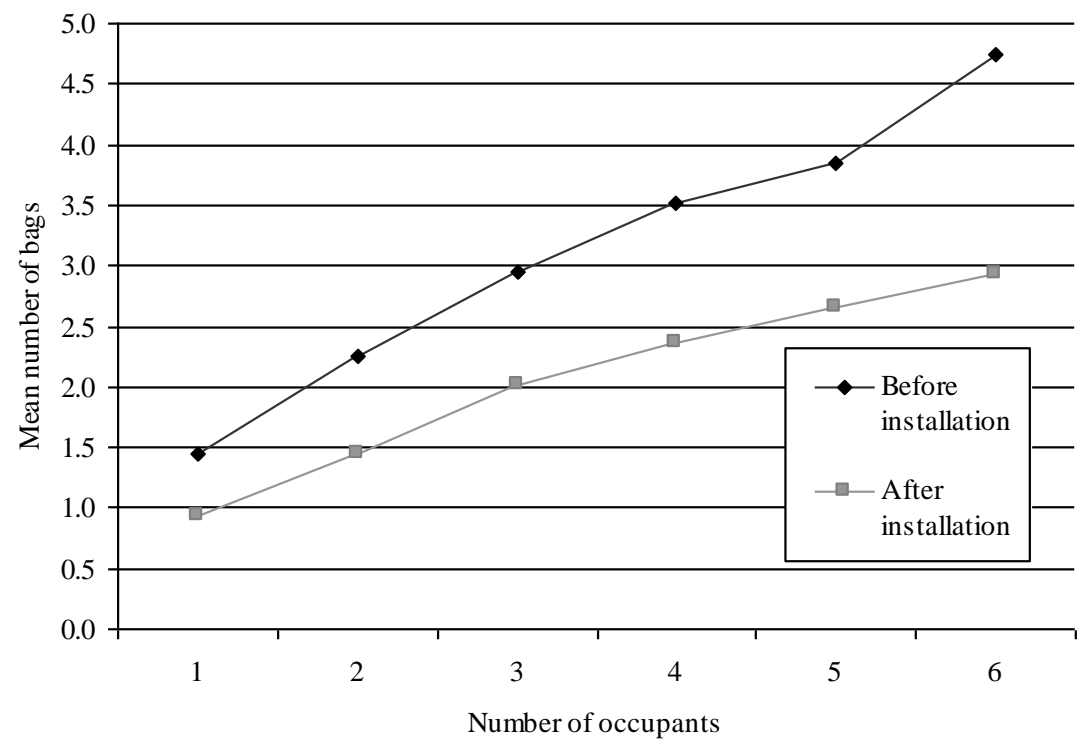

Fig. 4. Mean number of bags produced per household according to number of occupants before and after installation of the Green Cone digester. 


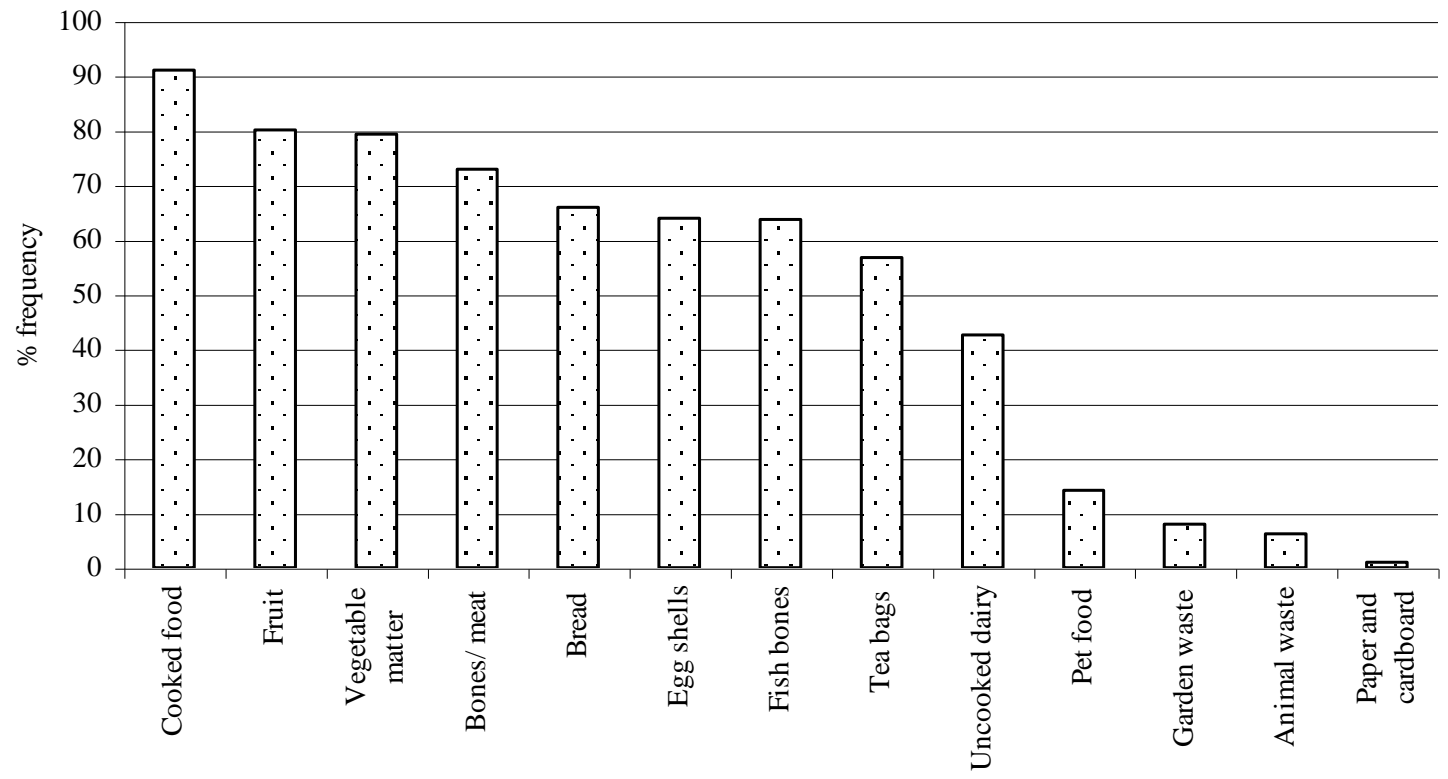

Fig. 5. Waste composition by percent response 


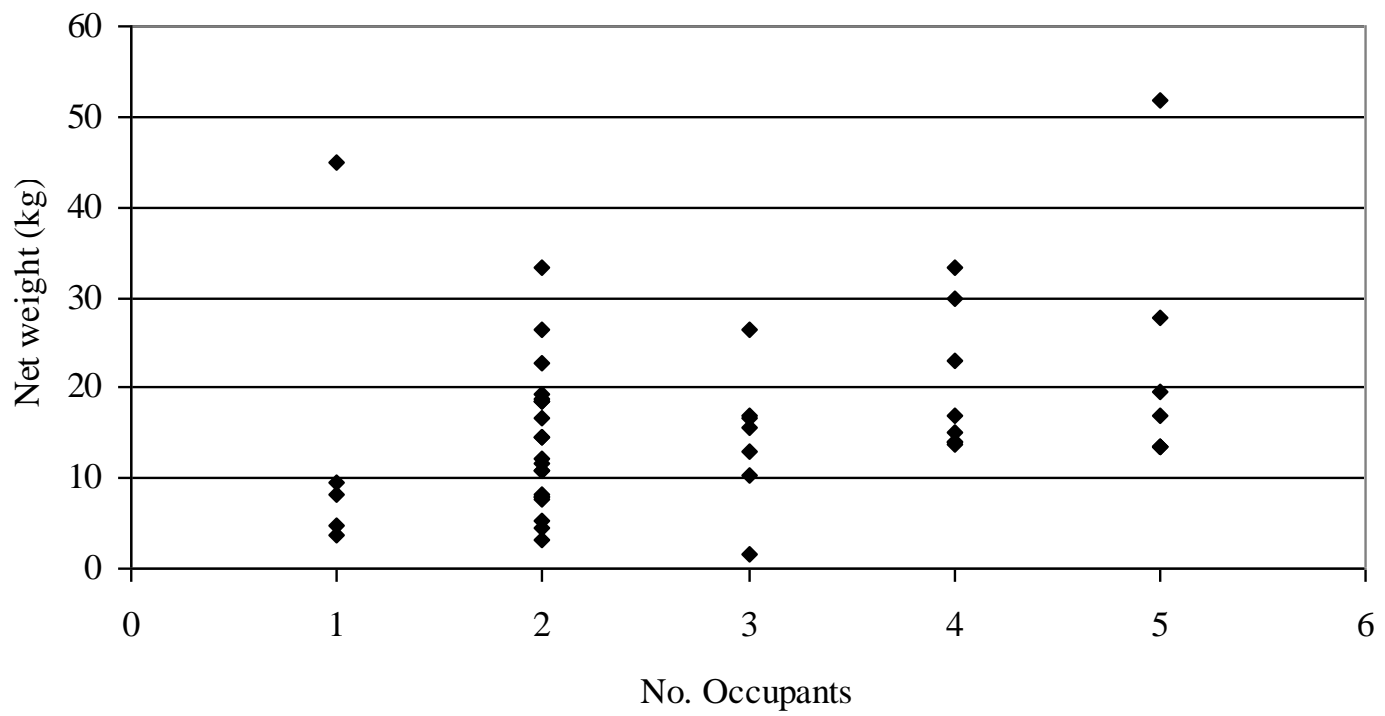

Fig. 6. Net weight per household according to number of occupants 